Carina Jia Yan Zhu, UNIVERSITY OF LETHBRIDGE, carina.zhu@uleth.ca

Diana White, UNIVERSITY OF CALGARY IN QATAR, dlwhite@ucalgary.edu.ca

Janet Rankin, UNIVERSITY OF CALGARY, jmrankin@ucalgary.ca

Christina Jean Davison, ZAYED UNIVERSITY, cj.davison@zu.ac.ae

\title{
Making Meaning from Student Evaluations of Teaching: Seeing Beyond Our Own Horizons
}

\section{ABSTRACT}

Within postsecondary education, the assessment of effective teaching has largely relied upon student evaluations of teaching. However, the process through which teachers make sense of their student evaluations is unclear. A research team of six undergraduate nursing students and four nursing educators explored the research question: How do nursing educators make meaning from their student evaluations of teaching? Gadamerian hermeneutics guided unstructured interviews with nursing educators working at a Middle East campus of a Canadian university. The interview transcripts were interpreted through a process of naive readings, rereadings, interpretive dialogues, and interpretive writing that generated the following hermeneutic interpretations:

1. Teachers make meaning of their student evaluation through generalized subjective characterizations of students and through their expressed intentions for their teacher-student relationships.

2. Some of these characterizations and expressed intentions obscured what truths could be learned from the student evaluations of teaching.

3. The experience of receiving critical student feedback invoked a personal response, at the same time, paradoxically, teachers worked hard to "not take it personally." We suggest the practice of deep listening as a way to understand students' feedback. The main takeaway message from this research is that teachers need a supportive and sustaining community of peers who are also open to listening deeply to the truths embedded in student evaluations of teaching.

\section{KEYWORDS}

student evaluations of teaching, nursing education, student feedback, hermeneutics, listening

\section{BACKGROUND}

Since their first use in Canadian and American universities in the mid-1920s, student evaluations of teaching have become institutional fixtures within higher education settings as direct or proxy measures of teaching effectiveness (Zabaleta, 2007). In addition to being a tool for quality assurance, student evaluations of teaching have also become the basis for career advancement (Emmelman \& DeCesare, 2007; Steiner, Holley, Gerdes, \& Campbell, 2006). For an educator, student evaluations of 
teaching play a major part in the assessment for promotion, tenure, and merit (Cleary, Happell, Lau, \& Mackey, 2013). For the student, evaluating one's teacher presents an opportunity to provide feedback with the goal of identifying areas for improvement in the content and delivery of a course and the competence of the educator (Steiner et al., 2006). The extent to which this feedback informs teaching practice largely rests on understanding how the educator processes this information.

\section{LITERATURE REVIEW}

The literature is rife with studies on student evaluation of teaching, most of which are quantitative in nature. Researchers have examined the validity of student evaluations of teaching (Frick, Chadha, Watson, \& Zlatkovska, 2010), student perceptions of evaluations of teaching (Emmelman \& DeCesare, 2007), and external factors that impact student evaluation of teaching (Clayson \& Haley, 2011). Some studies have also explored student evaluation of teaching from the educator's perspective, highlighting the importance of educator reactions to their evaluations (Moore \& Kuol, 2007), educator attitudes toward student evaluations of teaching (Smith \& Welicker-Pollack, 2008), and educator perceptions of the utility of student evaluations of teaching (Beran \& Rokosh, 2009). The research indicates that, in general, educators welcome feedback from students (Smith \& Welicker-Pollak, 2008) and view students as having the capability to provide an accurate assessment of teaching (Moore \& Kuol, 2007). Educators view student feedback as being useful despite divergent opinions on what constitutes effective teaching and whether this is captured in student evaluations of teaching (Schmelkin, Spencer, \& Gellman, 1997).

While existing research offers some foundational understanding of how student evaluations of teaching are received and perceived by educators, it represents a fragmented view of the educator's experience. Indeed, the authors of one study concluded that an in-depth, qualitative inquiry is necessary to fully capture the process through which educators make meaning from their students' evaluation (Smith \& Welicker-Pollak, 2008). Perhaps it is not surprising, then, that the complex, emotional, and intellectual process through which educators engage with their students' evaluations of their teaching is not easily quantified and reduced into a response on a Likert scale.

Factors beyond the educator's control such as age, gender, ethnicity, teaching settings (e.g., lecture versus lab), and class size, further influence student evaluations of teaching (Clayson \& Haley, 2011; Steiner et al., 2006). The extent to which educators take these into consideration while reflecting on their feedback is unclear. Troubling evidence suggests that receiving student feedback may, in fact, serve to alienate the educator and hinder professional growth when educators process their evaluations in isolation (Smith \& Welicker-Pollak, 2008) and that educators may hesitate to seek counsel for professional development based on the feedback (Smith \& Welicker-Pollak, 2008). Within this context, the process of receiving student evaluations of teaching may be disempowering and demoralizing for some educators and in turn, hinder the acceptance and utilization of student feedback.

Our literature review uncovered research generated from the disciplines of education, business, sociology, and social work. There is a dearth of research on student evaluations of teaching within nursing in general, and none from the perspective of the teacher. A literature search within the Cumulative Index to Nursing and Allied Health Literature database, limiting articles to the most recent 10 years, derived one article of relevance by Cleary et al. (2013) that offered insights into factors that have an impact on student evaluations of teaching and suggested strategies for nursing educators to 
respond to feedback. However, the process through which nursing educators make meaning from their students' evaluations of their teaching remains unclear. In search of further insights, we embarked upon our hermeneutic inquiry guided by the following research question: How do nursing educators make meaning from their students evaluations of teaching?

\section{METHODOLOGY}

With the aim to uncover meaning and interpretation of student evaluations of teaching among nursing educators, the study followed the tradition of Gadamerian hermeneutics. Hermeneutics is "an approach to the analysis of texts that stresses how prior understandings and prejudices shape the interpretive process." (Denzin \& Lincoln, 2005, p. 27). Unstructured interviews focused on the teacher's experience of receiving the results of student evaluations of their teaching were transcribed into text, which became the focus of the interpretation. The research intent was not to describe and define the experience stripped of context, but to interpret, understand, and derive meaning from the text, with recognition of the history and shifting context from which the topic arose and continues to evolve (Gadamer, 1989).

Specifically, Gadamerian hermeneutics is a philosophical approach within hermeneutics that points to the importance of the circumstances under which interpretation or understanding take place (Gadamer, 1989). In other words, Gadamer (1989) posits that everything is and has context, and for the purpose of interpretation, the data from participants was just as important as the history, perspectives, and opinions of the researchers.

\section{Study team}

This study was conducted at a branch campus of a Canadian university located in Doha, Qatar and funded by a research grant provided by Qatar National Research Fund through the Undergraduate Research Experience Program (UREP no: 16-018-3-007). Six undergraduate nursing students were recruited to be undergraduate researchers, and four faculty members served as faculty mentors. The undergraduate researchers were actively involved in the study design, data collection, interpretation, and dissemination of findings. Two undergraduate researchers and one faculty mentor formed triads that met weekly throughout data collection and analysis, wherein the undergraduate researchers' unique perspectives provided additional insights into the interpretations.

\section{Ethical considerations and recruitment}

The study received approval from the Conjoined Faculty Research Ethics Board at the University of Calgary. Six nursing educators, with at least one semester of teaching experience from which they received student evaluations of teaching, were recruited to participate in the study. Recruitment posters were displayed around campus, and the undergraduate researchers attended a nursing faculty meeting to explain the research project. After the nursing faculty meeting, one of the faculty mentors sent out an email to nursing faculty members to reiterate the call for volunteers. The first six faculty members to volunteer who met the inclusion criteria were selected for the study. The participants ranged from three to 30 years in teaching experience. 


\section{Data collection}

Each undergraduate research pair conducted two participant interviews that were organized with attention to possible discomfort related to prior or ongoing student teacher relationships. Interviews were conducted using a semistructured interview guide; the audio-recorded interviews ranged 90 to 120 minutes in length. All participants chose their pseudonyms for transcription. The interview guide provided the novice undergraduate researchers with a starting place for the interview, although in a true hermeneutic interview, the interviewee is encouraged to take their own path into the topic (Moules, McCaffrey, Field, \& Laing, 2015). In all of the interviews, following the introduction, the undergraduate researcher asked a direct question about the participant's experience of receiving the student evaluations, with a focus on an experience that stood out as the most poignant. At the conclusion of each interview, the participant was asked if he or she had any additional insights into the topic beyond what had been discussed. The participants were not asked specifically about a particular evaluation tool; instead, they were asked to draw from any previous experience with student evaluations of their teaching. At the school of nursing where the research was conducted, the evaluation tool consisted of Likert metrics and brief qualitative comments.

\section{Data analysis}

The hermeneutic circle, an element of Gadamerian hermeneutics, guided our interpretative approach. In the hermeneutic circle, each researcher progressed through a naive reading of interview transcripts to formulate initial impressions, followed by an interpretive reading for patterns of meaningful "parts," followed by an interpretation of the "whole" (Speziale \& Carpenter, 2003). This iterative process involved "recognizing the particular, isolating understanding, dialoguing with others about interpretations, making explicit the implicit, and then finding language to describe it" (Moules, 2002 , p. 31). The analysis relied upon the researchers' prejudices and biases to provide the lens through which the interview transcripts were examined and interpreted. This assimilation of the researchers into the analysis allowed for the illumination of new understanding or interpretation.

We intentionally avoided using thematic analysis, as the process of finding themes fractures the data, which results in a flat retelling of the narrative stripped of context (Moules, 2002). Instead, our interpretation involved moving between individual readings, reflective writing, and audio-recorded discussions within the triads. The whole research team then met to reexamine the interview transcripts and the preceding interpretive dialogues, which were also transcribed. The group worked together to identify the various interpretive threads ("parts") in order to build a "whole" of understanding. This approach to analysis was particularly appropriate, and perhaps serendipitously so, within the context of working in a team composed of both faculty members and undergraduate students. The goal of analysis was, therefore, not to represent the experience but to expand understanding beyond what each participant or researcher might have comprehended prior to the research, in order to establish new meaning, contribute insight, and realize new knowledge of the topic. In this regard, the students' contribution to the interpretation of the texts was a considerable strength of the study. The student researchers expressed sadness and concern when they understood the teachers' distress. They responded with deep interpretive empathy despite revelations from the data that teachers tended to characterize students negatively. 


\section{INTERPRETATIONS}

The seemingly simple intent of student evaluation of their teachers - to assess teaching at the institutional level - is taken up by teachers in a rather complex matrix of emotional response and rationalization. The process of making meaning of student evaluations of teaching is one fraught with discrepancies. Teachers' efforts to distill useful guidance and insights from their evaluation data emerged as a challenging, often painful, and confusing struggle. When asked the question, "From previous student evaluations, what was the most poignant piece of feedback you received from your students?," all of the teachers offered responses that focused on negative evaluations - a focus that is consistent with an established psychology that suggests negative events have greater impact on individuals than positive ones (Baumeister, Bratslaysky, Finkenauer, \& Vohs, 2001). The interpretations we developed reveal how teachers use the evaluations to construct beliefs about who they are as teachers, who the students are as learners, and what the nature of their student-teacher relationship is. We discuss our hermeneutic interpretations below.

\section{Meaning making through intentions and filters}

Teachers described their teaching intentions and the student-teacher relationship in various ways, and these served as filters through which student evaluations were read. Some teachers intended to be a relational facilitator; some intended to work hard for the students; and some described the energy they expended to be passionate, knowledgeable, and engaging.

Some teachers made meaning from their evaluations through beliefs about students and teachers being equals in the learning space (e.g., "meshing together"), while other teachers made the analogy to a salesperson-customer relationship (e.g., "selling the product of education"). For some teachers, the relationship with students was akin to that of an actor-on-a-stage performing for an audience of students.

Using their own plans and intentions for what they were trying to accomplish, teachers constructed a picture of their students as they reviewed the feedback from their students' evaluations of their teaching. Some teachers talked about students taking responsibility for their learning. A teacher, in response to her evaluations, said,

You know, with children I might do something different but with adult learners I felt, you are adult learners.

Other teachers talked about students' motivations, questioning whether or not students genuinely wanted to learn, or were only concerned with grades:

But if-if-if the grades are not quite up, like-like are not up where students would like them to be, there seems to be a correlation there as well that if people - if students are really unhappy with their marks, that you'll see that come through in the evaluations.

So therefore, you don't give the student the grade they want and they get mad at you or they give you a negative evaluation. 
If teachers assessed that the students received lower grades than expected, they believed that the teacher would, in turn, receive a low grade on the students' evaluations. Teachers drew the conclusion that low grades equaled low student evaluations to explain critical feedback.

Teachers were also critical about how students completed the evaluations at the end of each term. They filtered feedback using their impressions about students' thoughtfulness (e.g., whether or not students are thinking about the person who will read the comments) and their opinions about whether or not students have the requisite knowledge to fill out the evaluations appropriately (e.g., students do not understand the evaluation tool).

Another filter through which teachers responded to their evaluations was the skeptical belief that the tool was not internally valid. Teachers believed that the tool did not measure teaching or learning. Rather, it was an outlet for students to voice their frustrations and a measure of teacher popularity among students:

Often it's about your popularity than it is about your teaching... I think it's about "Do we mesh?"

One teacher questioned whether the evaluations measured teaching effectiveness or students' general attitude towards the subject being taught. This teacher acknowledged that students need an outlet for feedback about the course and about the instructor, but the two get mixed up in the student evaluations of teaching:

The evaluation like is measuring... just the teaching or if it's also the course and the teaching... your complaints about the course would probably end up with your evaluation of the teacher as well.

This prompted one teacher to suggest that students should be instructed to

[e]valuate the instructor, not the room, not the lighting, not the acoustics, not the other students, how the teaching of the actual instructor is.

Thus, for courses designed around nursing concepts that the students found difficult, not relevant, or misplaced in the curriculum, teachers believed that students conflated their frustration into critique about the teacher. Indeed, it may have been a curriculum, facilities, or scheduling issue that disrupted how students experienced the course.

\section{Amplifying the noise}

The term noise has its etymological roots in the Old French word noise, meaning "disturbance, uproar" (Noise, n.d.). Within cognitive sciences, signal detection theory defines noise as the background within which a signal or a message is embedded (Tanner \& Swets, 1954; Green \& Swets, 1966). We suggest that teachers responded to critical evaluation as though it was noise-the unpleasant uproar of critical feedback conveyed through harsh and emotive language led teachers to characterize students as bad, to consider student evaluations of teaching as useless, and to judge the feedback as invalid. The 
teachers' beliefs about students and student feedback generated more noise that further obscured key messages about their teaching.

Instead of the feedback being considered as an indication of something going wrong within the teaching-learning environment, the students were targeted as the problem. Characterization of the bad student was very much a part of the evaluation experience. For example, one teacher expressed less patience with

$[s]$ tudents who don't want to work hard and who want grades for just being there... like a certificate program almost, rather than..1 have to learn these things, I need to actually get the knowledge to be a nurse."

The assessment of the students' motivations, laden with values and assumptions about nursing, helped this teacher to dismiss negative feedback. We found similar negative characterizations of students in previously published research on student evaluations of teaching, wherein students were said to require spoon-feeding and engage in only surface learning (Ballantyne, Borthwick, \& Packer, 2000). Powell, Rubenstein, Sawin, and Annan (2014) further suggested that students are passive learners and that this is implicated in negative student evaluations of teaching.

Another teacher, who indicated that students are the bedrock of what makes the job worthwhile and rewarding, also rejected negative feedback by rendering the students' evaluations as invalid and lacking credibility:

They've grown up in a system where perhaps they don't have the best study skills, they have relied on memorization and not thinking. They have always received maybe high marks that perhaps have been inflated ... they get very disappointed if they don't get those high grades. And then they lash out maybe, or at their instructors' right?

The idea that students' receipt of bad grades will lead to bad evaluations was pervasive amongst the participants. In the literature, there was evidence to suggest that student evaluations of teaching are affected by student grades (Clayson \& Haley, 2011; Steiner, Holley, Gerdes, \& Campbell, 2006). Our interpretation suggests that in order to uncover the message about one's teaching, we must question this clamorous truth.

To illustrate what is meant by uncovering or listening to the signal, we draw from the experience of one of this study's authors (C. Zhu), who received her evaluations while analyzing the interview transcripts for this research. The students in her community health nursing course had struggled with two difficult exams, specifically on sections involving calculations of disease incidence and prevalence. As expected, scores on the evaluations were low across the board, with narrative comments that characterized her as an ineffective, disengaged teacher. Normally, she would have dismissed this feedback, attributing it to students being upset about not receiving the marks they were expecting. This time, having been immersed in the stories from the transcripts she was compelled to hear something different, beyond the usual noisy belief that bad grades equal bad evaluations. She saw the students' frustration that lurked behind the low scores; she sensed that the epidemiological additions to the course were misaligned with the students' expectations of what a community health nursing course ought to 
cover. It was frustrating, unexpected, and disappointing for the students, not just with their grades, but with their learning, of which grades were a part. The interpretive work with the interviews, the literature, and the combined wisdom of the research team provided a way to understand aspects of the evaluation experience that remain concealed within current understandings. We were inspired to look beyond our beliefs, and it was here that the student researchers' insights helped to uncover unsettling challenges that student evaluations generated for teachers.

All of the teachers on the research team had been subjected to strongly worded comments in their students' feedback. Lindahl and Unger (2010) uncovered similarly unforgiving comments in their study, with some teachers being told "She does not know how to teach. I have not learned a new thing this semester and I want my money back"; "'His teaching methods are more suitable for an elementary school class"; " "I learned nothing of use. I know high school students who can teach better than her" (p. $72)$.

How does students' anger contribute another layer of noise that precludes teachers from deciphering the signal within the evaluations? Our next hermeneutic interpretation suggests that we can open the evaluation experience by bringing awareness to the contradictions that lie within the teacher's experience with students and their perceptions of student feedback.

\section{Contradiction: Contra in diction}

As we moved beyond surface features of teachers' experiences of student evaluations, we uncovered deep contradictions in how they interpreted and responded to them. The word contradiction has its etymological roots in "a reply, an objection, a counterargument . to speak against."

(Contradiction, n.d. a). In contemporary times, contradiction has come to mean inconsistent or opposing elements or statements (Contradiction, n.d. b). The complexity of teachers' experiences of student evaluations was what drew us to the topic, and in hermeneutic terms, how it addressed us. Uncovering the contradictions that emerged from how teachers discerned meaning from student evaluations was a significant feature of our interpretation as we "paid reflexive attention to different standpoints and ways of seeing the topic" (Moules et al., 2015, p. 122).

Within the teachers' narratives, we found opposing statements about how the teachers viewed themselves in relation to students. One teacher, who, at the beginning of the interview, described her teaching relationship with students as that of a salesman to customers, later disclosed a commitment to students that was clearly more than that of a salesman trying to close a sale:

Nine of the 17 students perceived me as disrespectful. And this is despite me giving them enormous coaching, one-to-one help, tons and tons offeedback... I was giving a lot of work, a lot of assistance to help them with their writing skills ... we bend over backwards.

Another teacher, who initially likened the act of teaching to being an actor on stage performing for a passive audience of students, later said,

I think that my teaching style is more, kind of, shared learning... I learn as much from the students as they learn from me... particularly around the culture and countries of 
origin... I would say I have more of a shared learning model that guides me... I'm more of a facilitator than a teacher.

It was evident that both of these teachers cared deeply about their students and had invested time and effort into coaching, guiding, and counseling their students. Their commitment to good teaching contradicted the impersonal relationships connoted by a sales pitch or a performance. In this vein, the teachers' contradictory self-descriptions seemed to activate the etymological roots of language - the teachers were drawn into constructing counterarguments to the critical feedback they received. Perhaps it was within the characterization of a temporary and superficial relationship, like that of a salesperson to a customer, that the teachers could make sense of the critical feedback from students. The oppositions in the teachers' language, or contra in diction, comprised a core element of how teachers could understand students' critical feedback.

We found another example of contra in diction in the tension between wanting feedback and readily dismissing feedback, particularly students' negative comments. Teachers told us that student feedback was imperative to aspects of their teaching and course design. Feedback was something they deserved to get. Paradoxically, however, they also held steadfast to the sentiment that negative feedback was solely about students receiving poor grades. In essence, teachers wanted students to have a voice, but the only voices they listened to were those that echoed what they wanted to hear:

The fact that they haven't done their best is why they write the really negative comments. It's not so much about you as the faculty member, but their disappointment and it's how they deal with it. That's the way I look at it.

I also know if I've had students who have not performed as well as I'd hoped and that I've had to talk to them about that or if I've failed students, I know that student is going to give me a bad evaluation.

The teachers' explanation, and subsequent rejection, of critical feedback created an antinomy that we suggest is a central feature of the evaluation experience. It seemed as though each teacher experienced ambivalence, their ideas and attitudes about student evaluations triggering internal conflict as to what to do with feedback that spoke against (contradicted) what they held to be true. It is an intensely personal process, one laden with doubt and defeat. We come to our next interpretation of letting it be personal, because it is.

\section{It is personal}

"The nurse, in the therapeutic use of self, rejects approaching the patient-client as an object and strives instead to actualize an authentic personal relationship between two persons" (Carper, 1978, p. $18)$.

Among all of the teachers, we discerned a palpable desire to connect genuinely and relationally with students. The teachers were committed to treating students as partners in decision making and equals in the shared experience of teaching and learning. In instances of unexpectedly negative or disappointing feedback on the student evaluations, it evoked a strong response. The language of being 
“devastated” expressed the depth of this teacher's evaluation experience. As one teacher told an undergraduate researcher:

I felt devastated. Because just like you, I never want a negative evaluation from a paper. Teachers never want negative evaluations. We do our best just as you do your best.

Other teachers' interviews were also fraught with deeply personal feelings of being hurt, angry, disappointed, and ashamed-all intimate, emotional reactions to students' comments on the evaluations. The teachers' expressions of these feelings seemed, again, contradictory to what these same teachers told us about how they intellectualized and distanced themselves from the feedback through the construction of the bad, unmotivated, grade-seeking student. Nonetheless, there was a tangible current of personal vulnerability that the teachers experienced in the face of the student evaluations. The evaluations influenced whether or not a teacher felt accepted and respected by students, and this was clearly important to them. Critical feedback triggered deep feelings of being rejected. One teacher explained the process of reading her evaluations as wanting to find out what the students "hated" about her and the class:

What I'm more concerned about is the very poor section. So if I have a bunch of those, I actually will look at those and then I'll try and see "Okay, what did they — what did hate about it and what did they hate about me?"

Some teachers were ashamed of the negative feedback and embarrassed at the thought of sharing it with colleagues:

Well, I guess I-I would be embarrassed to share that with anybody.

But often times, we take this feedback, and we don't share it with other people. Um, because especially ifit's bad information, you don't want to share it with anybody else. So, sometimes it can be devastating.

Clearly, the response to a disappointing evaluation is deeply emotional. In another contradictory twist, having disclosed deep emotional feelings evoked by critical feedback, several teachers described how they work at not taking it personally:

Um, so you have to-it's not easy, but you have to put a bit of a hard skin on, I guess, and take those lumps from students, sometimes.

That, um, it's not that [student evaluations] don't affect me as a person, because you'd be silly if someone evaluated you and you said it doesn't. It's just that I have a personality that I don't-I don't get depressed over them; I don't hardly get upset; I don't anything. 
Um, uh and I think the challenge is to not take it so personally and not get really upset with it, but to actually transfer it into action, so that you do something with it, and you take it as constructive feedback. 'Cause, you know, we struggle with that too, right?

We bravely suggest that the well-intentioned but dismissive colloquialism "don't take it personally" is a flawed wisdom.

Our person-ness is a part of how we teach. Barbara Carper's (1978) seminal work on the patterns of knowing in nursing, from which we drew the opening quote to this interpretation, suggested that the therapeutic use of self is foundational to the personal way of knowing, exhorting us to "stand in relation to another human being and confronting that human being as a person" (p. 18). Nursing educators use their therapeutic selves in teaching, and critical feedback about the teaching, then, is also about the person behind the lectern. Our interpretation suggests that it is not possible to not react personally to personally directed comments.

Returning to a question we posed earlier-how does students' anger close down how a teacher might respond to evaluations of teaching? We suggest that it is the act of depersonalizing the feedback that creates another powerful layer of noise, obscuring the signal within critical student evaluations. It invalidates the genuine emotions teachers experience when reading the negative and hurtful comments, and distances teachers from students' anger or frustration - which students, too, experience at a profoundly personal level when they express themselves in their evaluations.

Our suggestion to respond to student evaluations of teaching personally does not mean teachers should take ownership of harsh comments from students. Rather, we mean for teachers to consciously acknowledge the feelings of hurt, disappointment, and shame. Creating the space for these intensely personal reactions evoked by the evaluations is, in our view, an important step towards listening deeply to a truth that may lie beyond what is safe and familiar.

Within the subdiscipline of family nursing, nurse clinicians often invite family members to share their thoughts, actions, and emotions in the face of a critical illness. These illness narratives of fear, loss, and sadness help families cope by acknowledging their struggles and by signaling to others the need for support. Tapp (2001) coined this as "conserving the vitality of suffering" (p. 261). Similarly, critical student feedback compels us to invite dialogue from our peers in sharing disappointment and in creating community.

\section{DISCUSSION}

Within the current experiences of student evaluation of teaching offered by our study participants and fellow colleagues, teachers worked to intuit the students' messages by recalling their intentions as teachers (e.g., to work hard for the students, to be passionate, to be knowledgeable) and by filtering out critical feedback. There was a palpable sense of self-protection in the use of filters, insofar as they allowed teachers to discard feedback that was foreign and uncomfortable to their self-identity as teachers. Social psychology refers to this as protective adaptations (Sherman \& Cohen, 2006), wherein cognitive strategies are utilized to construe a situation that attenuates the threat to self-identity and emotional wellbeing. In the case of our participants, the threat of critical feedback was attenuated by construing students as unthoughtful and unable to evaluate teaching using an internally invalid evaluation tool. 
Critical student evaluations of teaching evoked emotional, personal responses from the teachers, while, paradoxically, teachers were compelled to not take the feedback personally. The process of receiving student feedback is profoundly vulnerable and, at times, contradictory. In the face of critical comments, teachers try to make sense of how their students' experiences of them can be so different from what they had intended or expected. We suspect that our findings may have relevance beyond the discipline of nursing education. However, more research is needed to confirm this hunch. It is possible that within nursing, with its emphasis on relational practice and empathy, that negative feedback is attributed different meanings by nursing teachers than would be uncovered in teaching other disciplines.

Our hermeneutic inquiry into nursing educators' experience with student evaluations of teaching led us to an expanded understanding of listening. Maturana (1988) suggested that we listen to each other in one of two ways - to see if the other agrees with what we already know (listening to ourselves) or to find a truth in what the other person is saying (listening to the other). The data, in its extremes and particulars and taken together as a whole, provided insight into a practice of selective hearing - of listening only to our own truths.

We propose an approach that involves Maturana's (1988) latter conceptualization of listening, one that involves listening, wholeheartedly, for a truth that extends beyond that which we find familiar or comfortable. We believe that attentive, deep listening can mitigate some of the tensions and discomfort that student evaluations generate for teachers. When confronted with critical student feedback, the teacher listens deeply by preserving the space for emotive reactions and by trusting that all statements are someone's truth, at some moment in time, and therefore, worthy of attention. Moules et al. (2015) referred to this as "listening right behind your eyes", requiring "watchfulness, openness, and searching to find a truth in what the other is saying" (p.94).

We dare to suggest that deep listening is the antidote to defensiveness. When we stop listening for a truth we already know, we stop needing to defend. In other words, when we truly listen to our students, we are not listening for affirmation or rejection of ourselves as teachers.

To be a deep listener to student feedback, teachers need support at the individual and community levels. Personally, we need to develop an understanding of our teaching that cannot come solely from the student evaluations. Some scholars of teaching and learning have suggested that inviting fellow peers to observe and evaluate one's teaching can offer valuable insights (Berk et al., 2004; Hammersley-Flecher \& Orsmond, 2004). Communally, teachers have to seek out peers who are also committed to listening deeply and attentively to the expression of the students' experiences. While it is beyond the reach of our findings to suggest what a review process of student evaluations of teaching may look like in practice, we offer the hermeneutic circle as a device for deep listening. After all, the hermeneutic circle was what allowed us to listen deeply to the transcripts of the research interviews.

In a supportive environment of two or three colleagues, starting with a set of student evaluations that the nursing teacher has chosen to share, each member proceeds through an initial reading, making note of initial impressions (naïve reading); then an interpretative reading for patterns of meaningful "parts" (interpretative reading); then reflective writing on the meaningful parts using their experience, bias, and prejudice as foreground (interpretive writing). Finally, the teachers would convene in conversation with each other to understand the "whole" - the teacher, his or her peers, and the student evaluations (interpretive dialogues). The purpose of the interpretive dialogues is to allow the teachers' own truths to shift as they expand understanding beyond what truths they may have held prior to this 
process. The use of the hermeneutic circle may help teachers establish new meaning from hearing the voice of the other (e.g., the students' and colleagues').

We do not envision deep listening to be for the fainthearted teacher. It is hard work. We believe it is a way of being that can only be honed from humility, dialogue, and being held in community of other teachers who are also committed to listening to the other. Roxå and Mårtensson (2009) suggest that most teachers have a small 'significant network' of individuals with whom they have sincere conversations about their teaching, wherein they express ideas different from what they would say in a broader social context. The privacy and mutual trust in these conversations, combined with the atmosphere of idea testing and problem-solving make them fruitful ground for learning about teaching. We suggest that engaging with these significant networks before an annual performance review would be an opportune time for teachers to listen deeply to multiple sets of student feedback. While the intention of the requisite annual performance review may be focused on merit, tenure, and/or promotion, it nevertheless requires the teacher to reflect on the past year's accomplishments in teaching, scholarship, and service. With a keen eye on teaching, listening deeply to student evaluations at this juncture may also help to identify areas for growth in the coming semesters.

\section{CONCLUSION}

Deep listening implores us to trust that each student knows something about how they have experienced learning. From this place, we become open to growth and change. Deep listening demands that we understand that student evaluations of teaching are often the students' only formal way of expressing tensions not just with the teacher, but with the entire learning journey (e.g., course content, postsecondary education, class size, and scheduling). Deep listening diminishes the noise generated from our beliefs about students and allows us to hear key messages embedded within the students' evaluations.

We suggest that to listen deeply, teachers do the following:

1. Establish review circles with two to three peers who are also committed to listening deeply to student feedback, with whom the teacher feels safe to share feedback from the student evaluations.

2. Ask questions of the student evaluation data, individually and within the feedback circle, using a process similar to the hermeneutic circle in understanding the parts and whole of the student evaluations of teaching.

3. Work to respond to the feedback within the contextual truths that teachers and students experience together-such as the tensions created by large groups; rigid course outlines; dry topics that are difficult to make relevant; course placement in the curriculum; scheduling of the class; classroom or technological issues; and so forth.

4. Work to fuse the students' experiences and feedback with the teacher's own truths to arrive an expanded understanding of the feedback.

It would be ideal to include students in conversations that support teachers' deep listening. However, in the presence of negative characterizations of students that accompany some teachers' responses to student evaluations, it is our view that including students in structured deep listening 
processes would require careful, ethical facilitation. The students and teachers of our research team established collegial, nonhierarchical relationships long before we entered the interpretive discussions. It was within the relationship of research colleagues that we could work through our positioning as student and teacher.

We suggest teachers seek out their review peers organically, which is not to say that the review process should be unstructured. We recommend against mandating a review process for student evaluations of teaching, lest it turns into a ritualistic practice robbed of meaning for teachers. We strongly believe that entering our recommended practice of deep listening into formally scrutinized institutional processes introduces a risk of undermining its intended purpose. We envision that the teaching and learning specialists at the education institution may be able to facilitate the matching of teachers with experience in review of student evaluations of teaching using the hermeneutic circle with those who are naïve to the process. Lastly, documenting our dialogue with the transcribed interviews informed our insights as researchers and teachers, and we would suggest that this may be an important element of the review process to elicit patterns in the students' feedback over time.

The interpretative conversations during our hermeneutic work on this study allowed the teachers on the research team to engage in complex, introspective, and passionate discussions about our own philosophies of teaching, our approaches to students, and our own biases. It has allowed us to share critical, negative, and abrasive comments without absorbing them in isolation. It has helped us to read our student evaluations of teaching with a different perspective, to listen deeply and attentively for the truths that may lie in the students' expressions of their experience.

\section{ACKNOWLEDGMENTS}

To our undergraduate researchers - Ebtesam Jassim, Asma Mohamood, Nabila Chaabna, Sara Al Qahtani, Mina Mohammadpour and Sara Hakim-your contributions to this research project were invaluable. Thank you for your dedication, your hard work, and your insights. It was a delight and distinct pleasure working alongside you. To our study participants, who are also our teaching colleagues, thank you for your candidness in sharing your own unique and complex experiences of receiving and processing student feedback. We also offer our humble thanks to Dr. Nancy Moules, who was generous with her expertise and guidance on the methodology of this study. Finally, we thank the Qatar National Research Fund (a member of Qatar Foundation) for its financial support; this research study was made possible by UREP grant \#16-018-3-007. The statements made herein are solely the responsibility of the authors.

Carina Zhu is an Instructor with the Faculty of Health Sciences at the University of Lethbridge (Canada). Her areas of passion include public health, harm reduction and community health nursing.

Diana White is an Instructor at University of Calgary in Qatar. Her areas of passion include treatment adherence in chronic disease management, wellness care in primary care services, and nursing education.

Janet Rankin is an Associate Professor at University of Calgary (Canada). Her program of research explores the social organization of nursing work and nursing education. 
Christina Davison is an Instructional Designer at Zayed University (Dubai). Her research interests are in educational development, transnational teaching, educational technology, and student engagement.

\section{REFERENCES}

Ballantyne, R., Borthwick, J., \& Packer, J. (2000). Beyond student evaluation of teaching: Identifying and addressing academic staff development needs. Assessment \& Evaluation in Higher Education, 25(3), $221-$ 236. https://doi.org/10.1080/713611430

Baumeister, R. F., Bratslaysky, E., Finkenauer, C., \& Vohs, K. D. (2001). Bad is stronger than good. Review of General Psychology, 5(4). 332-370.http://dx.doi.org/10.1037/1089-2680.5.4.323

Beran, T. N., \& Rokosh, J. L. (2009). Instructors' perspectives on the utility of student ratings of instruction. Instructional Science, 37(2), 171-184.https://doi.org/10.1007/s11251-007-9045-2

Berk, R. A., Naumann, P. L., \& Appling, S. E. (2004). Beyond student ratings: Peer observation of classroom and clinical teaching. International Journal of Nursing Education Scholarship, 1(1), 1-26. https://doi.org/10.2202/1548-923X.1024

Carper, B. (1978). Fundamental patterns of knowing in nursing. Advances in Nursing Society, 1(1), 13-24. Clayson, D. E., \& Haley, E. A. (2011). Are students telling us the truth? A critical look at the student evaluation of teaching. Marketing Education Review, 21(2), 101-112. https://doi.org/10.2753/MER1052-8008210201

Cleary, M., Happell, B., Lau, S. T., \& Mackey, S. (2013). Student feedback on teaching: Some issues for consideration for nurse educators. International Journal of Nursing Practice 19(S1), 62-66. https://doi.org/10.1111/ijn.12018

Contradiction. (n.d. a) Online Etymological Dictionary. Retrieved from http://www.etymonline.com/index.php?allowed in frame=0\&search=contradiction\&search mode $=$ none

Contradiction. (n.d. b). Merriam-Webster Online Dictionary. Retrieved from http://www.merriamwebster.com/dictionary/contradiction

Denzin, N. K., \& Lincoln, Y. S. (Eds.) (2005). The Handbook of Qualitative Research (3rd ed.). Thousand Oaks: Sage. Emmelman, D. S., \& DeCesare, M. (2007). College students' perceptions of their "best" and "worst" courses and instructors. International Review of Modern Sociology, 33(2), 227-244. https://scholarworks.merrimack.edu/soc facpub/2

Frick, T. W., Chadha, R., Watson, C., \& Zlatkovska, E. (2010). Improving course evaluations to improve instruction and complex learning in higher education. Education Technology Research Development, 58(2), 115136. https://www.jstor.org/stable/40603152

Gadamer, H-G. (1989). Truth and Method (2nd rev. ed.) (J. Weinsheimer \& D. G. Marshall, Trans.). New York: Continuum.

Green, D. M., \& Swets, J. A. (1966). Signal Detection Theory and Psychophysics. New York: Wiley. HammersleyFletcher, L., \& Orsmond, P. (2004). Evaluating our peers: Is peer observation a meaningful process? Studies in Higher Education, 29(4), 489-504. https://doi.org/10.1080/0307507042000236380

Lindahl, M. W., \& Unger, M. L. (2010). Cruelty in student teaching evaluations. College Teaching, 58(3), 71-76. https://doi.org/10.1080/87567550903253643

Maturana, H. R. (1988). Reality: The search for objectivity of the quest for a compelling argument. Irish Journal of Psychology, 9(1), 25-82.https://doi.org/10.1080/03033910.1988.10557705

Moore, S., \& Kuol, N. (2005). Students evaluating teachers: Exploring the importance of faculty reaction to feedback on teaching. Teaching in Higher Education, 10(1), 51-73. https://doi.org/10.1080/1356251052000305534

Moules, N. J. (2002). Hermeneutic inquiry: Paying heed to history and Hermes-An ancestral, substantive, and methodological tale. International Journal of Qualitative Methods, 1(3), Article 1. https://doi.org/10.1177/160940690200100301

Moules, N. J., McCaffrey, G. P., Field, J. C., \& Laing, C. M. (2015). Conducting Hermeneutic Research: From Philosophy to Practice. New York: Peter Lang.

Noise (n.d.). Online Etymological Dictionary. Retrieved from https://www.etymonline.com/word/noise\#etymonline v 9738 
Powell, N. J., Rubenstein, C., Sawin, E. M., \& Annan, S. (2014). Student evaluations of teaching tools: A qualitative examination of student perceptions. Nurse Educator, 39(6), 274-279. https://doi.org/10.1097/NNE.0000000000000066

Roxå, T., \& Mårtensson, K. (2009). Significant conversations and significant networks-exploring the backstage of the teaching arena. Studies in Higher Education, 34(5), 547-559. https://doi.org/10.1080/03075070802597200

Schmelkin, L. P., Spencer, K. J., \& Gellman, E. S. (1997). Faculty perspectives on course and teacher evaluations. Research in Higher Education, 38(5), 575-592. https://doi.org/10.1023/A:1024996413417

Sherman, D. K., \& Cohen, G. L. (2006). The psychology for self-defense: Self-affirmation theory. In M. Zanna (Ed.), Advances in Experimental Social Psychology. vol. 38 (pp. 183-242). New York: Academic Press.

Smith, K., \& Welicker-Pollak, M. (2008). What can they say about my teaching? Teacher educators' attitudes to standardized student evaluation of teaching. European Journal of Teacher Education, 31(2), 203-214. https://doi.org/10.1080/02619760802000248

Speziale, H. J. S., \& Carpenter, D. R. (2003). Qualitative Research in Nursing: Advancing the Humanistic Perspective (3rd ed.). Philadelphia: Lippincott Williams \& Wilkins.

Steiner, S., Holley, L. C., Gerdes, K., \& Campbell, H. E. (2006). Evaluating teaching: Listening to students while acknowledging bias. Journal of Social Work Education, 42(2), 355-376. https://doi.org/10.5175/JSWE.2006.200404113

Tanner, W. P., \& Swets, J. A. (1954). A decision-making theory of visual detection. Psychology Review, 61(6), 401409. http://psycnet.apa.org/doi/10.1037/h0058700

Tapp, D. M. (2001). Conserving the vitality of suffering: Addressing family constraints to illness conversations. Nursing Inquiry, 8(4), 254-263. https://doi.org/10.1046/j.1440-1800.2001.00118.x

Zabaleta, F. (2007). The use and misuse of student evaluations of teaching. Teaching in Higher Education, 12(1), 55-76. https://doi.org/10.1080/13562510601102131

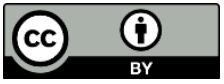

Copyright for the content of articles published in Teaching \& Learning Inquiry resides with the authors, and copyright for the publication layout resides with the journal. These copyright holders have agreed that this article should be available on open access under a Creative Commons Attribution License 4.0 International (https://creativecommons.org/licenses/by/4.0). The only constraint on reproduction and distribution, and the only role for copyright in this domain, should be to give authors control over the integrity of their work and the right to be properly acknowledged and cited, and to cite Teaching \& Learning Inquiry as the original place of publication. Readers are free to share these materials — as long as appropriate credit is given, a link to the license is provided, and any changes are indicated. 